\title{
Polyketide-Terpene Hybrid Metabolites from an Endolichenic Fungus Pestalotiopsis sp.
}

\author{
Chao Yuan,, Gang Ding, ${ }^{2}$ Hai-Ying Wang, ${ }^{3}$ Yu-Hua Guo, ${ }^{2}$ Hai Shang, \\ Xiao-Jun Ma, ${ }^{2}$ and Zhong-Mei Zou' ${ }^{2}$ \\ ${ }^{1}$ Institute of Medicinal Plant Development, Yunnan Branch, Chinese Academy of Medical Sciences and Peking Union Medical College, \\ Jinghong 666100, China \\ ${ }^{2}$ Institute of Medicinal Plant Development, Chinese Academy of Medical Sciences and Peking Union Medical College, \\ Beijing 100193, China \\ ${ }^{3}$ College of Life Sciences, Shandong Normal University, No. 88 East Wenhua Road, Jinan 250014, China
}

Correspondence should be addressed to Xiao-Jun Ma; mayixuan10@163.com and Zhong-Mei Zou; zmzou@implad.ac.cn

Received 23 February 2017; Revised 23 March 2017; Accepted 2 April 2017; Published 16 May 2017

Academic Editor: Lijian Xu

Copyright (C) 2017 Chao Yuan et al. This is an open access article distributed under the Creative Commons Attribution License, which permits unrestricted use, distribution, and reproduction in any medium, provided the original work is properly cited.

Five new polyketide-terpene hybrid metabolites (1-5) with highly functionalized groups, together with six known derivatives (6-11), were isolated from the endolichenic fungus Pestalotiopsis sp. Their structures were elucidated by extensive NMR experiments including ${ }^{1} \mathrm{H},{ }^{13} \mathrm{C}, \mathrm{HMQC}, \mathrm{COSY}$, and HMBC. The relative configurations of the new compounds were determined by analysis of coupling constants and ROESY correlations. The absolute configurations especially the secondary alcohol at C-15 in $\mathbf{1}$ and secondary alcohol at C-14 in 5 were established via the $\mathrm{CD}$ experiments of the in situ formed $\left[\mathrm{Rh}_{2}\left(\mathrm{OCOCF}_{3}\right)_{4}\right]$ complex with the acetonide derivatives. These compounds were tested for their inhibition activity against six plant pathogens. Compounds $\mathbf{1}$ and $\mathbf{5}$ exhibited pronounced efficiency against Fusarium oxysporum, and compounds $\mathbf{5}$ and $\mathbf{6}$ potently inhibited Fusarium gramineum with MIC value of $8 \mu \mathrm{g} / \mathrm{mL}$, which revealed the plausible ecological role of endolichenic fungus in providing chemical protection for its host lichen in the fungus-plant relationship. The biosynthetic pathway of compounds 1-11 was postulated for the first time, which paved the way for its further biosynthesis research.

\section{Introduction}

The highly prolific genus Pestalotiopsis often occurred on a broad range of substrata [1]. They could produce abundant diverse carbon skeleton compounds with many bioactivities [2]. Since discovery of the anticancer agent taxol from an endophytic fungal strain of the genus Pestalotiopsis sp. [3, 4], interest of bioactive compounds from this fungal genus has increased notably.

Endolichenic fungi inhabit the lichen thalli similarly to endophytes living in the intercellular spaces of healthy plant tissues [5]. Lichens are symbiotic organisms of photobiont and mycobiont. The photobiont provides the living space and nutrition for endolichenic fungi; in return, the endolichenic fungi might produce some secondary metabolites to help its host defend bio/abioattacks [6]. Chemical investigations revealed that endolichenic fungi could produce diverse secondary metabolites with significantly chemical ecological roles such as UV-protection, antiviral, and other biological activities [6-9]. Ambuic acid, a highly functionalized cyclohexenone metabolite with a wide range of biological activities, was first isolated from an endophytic fungus Pestalotiopsis spp. [10]. Later this bioactive compound was isolated from another two endophytic fungi Pestalotiopsis sp. $[11,12]$, which implied that ambuic acid and its analogs might be diagnostic metabolites in the chemical taxonomy of Pestalotiopsis sp. During our ongoing efforts to mine secondary metabolites from fungi inhabiting unique biotopes [13-16], an endolichenic fungus Pestalotiopsis sp. was targeted with purification of five new ambuic acid derivatives (1-5), together with six known ones (6-11) (Figure 1). Details of the isolation, structural elucidation, and bioactivity evaluation were reported herein. 
<smiles>[R]CC1=C(/C=C/CC[C@H](O)CI)C(=O)[C@]2(C/C=C(\C)C(=O)O)C[C@H]1[C@H]2O</smiles>

$$
1 \mathrm{R}=\mathrm{OH}
$$$$
2 \mathrm{R}=\mathrm{OAc}
$$<smiles>CCC[C@H](O)C/C=C/C1=C(CO)[C@H](O)[C@H]2O[C@]1(C/C=C(\C)C(=O)O)C2=O</smiles><smiles>[R]C(C)CCC/C=C/C1=C(CO)[C@H](O)[C@@H]2O[C@@]2(C/C=C(\C)C(=O)O)C1=O</smiles>

$9 \mathrm{R}=\beta \mathrm{OH}$

$10 \mathrm{R}==\mathrm{O}$<smiles>[R]C1C(/C=C/CCC[C@H](C)O)=C(COC(=O)O)[C@@H](O)[C@@H]2O[C@@]12CC=C(C)C(=O)O</smiles>

$3 \mathrm{R}=\alpha \mathrm{OH}$

$4 \mathrm{R}==\mathrm{O}$<smiles>[R2]CC1=C(/C=C/CCCCC)C([R1])[C@@]2(C/C=C(\C)C(=O)O)C[C@H]2[C@@H]1O</smiles>

$$
\begin{aligned}
& 6 \mathrm{R}_{1}=\alpha \mathrm{OH}, \mathrm{R}_{2}=\mathrm{OH} \\
& 7 \mathrm{R}_{1}=\alpha \mathrm{OH}, \mathrm{R}_{2}=\mathrm{OAc} \\
& 8 \mathrm{R}_{1}==\mathrm{O}, \mathrm{R}_{2}=\mathrm{OH}
\end{aligned}
$$<smiles>CCCCC/C=C/C1=C(CO)C(=O)C[C@H](O)[C@H]1O</smiles>

11

FIGURE 1: Chemical structures of compounds 1-11.

\section{Materials and Methods}

2.1. Instruments. Optical rotations were obtained on a PerkinElmer 241 Polarimeter (Waltham, MA, USA), and CD measurements were performed with a JASCO J-815 Spectropolarimeter. UV data were measured using a Beckman Coulter DU 800 spectrometer (Tokyo, Japan). IR spectra were recorded using a Shimadzu FTIR-8400S spectrophotometer (Tokyo, Japan). NMR spectra were acquired with a Bruker 500 (Munich, Germany) instruments operating at $500\left({ }^{1} \mathrm{H}\right)$ and $125\left({ }^{13} \mathrm{C}\right) \mathrm{MHz}$ using the solvent signals $\left(\mathrm{CD}_{3} \mathrm{OD}: \delta_{\mathrm{H}}\right.$ $\left.3.31 / \delta_{\mathrm{C}} 49.0 \mathrm{ppm}\right)$ as references. The HRESIMS experiments were carried out on a TOF-ESI-MS (Waters Synapt G2, USA) equipment. HPLC for purifications were performed on a Waters 2489 Semiprep-HPLC System using an ODS column (RP-18, $250 \times 10$ mm, YMC Pack, $5 \mu \mathrm{m}$; detector: UV; Kyoto, Japan). Sephadex LH-20 (Pharmacia Biotech AB, Uppsala, Sweden) and silica gel (80-100, 100-200, and 200-300 mesh; Qingdao Marine Chemical Plant, Qingdao, China) were used for column chromatography, and thin layer chromatography (TLC) was carried out with glass precoated silica gel GF254
(0.20-0.25 mm; Qingdao Marine Chemical Plant, Qingdao, China).

2.2. Fungal Material. An endolichenic fungus Pestalotiopsis sp. was isolated from the lichen Cetraria islandica (L.) Ach. collected from Laojun Mountain, Yunnan Province, China, and was identified by one of the coauthors (Hai-ying Wang) based on the nuclear rDNA ITS sequences (GenBank: KY275424). The fungal strain was cultured on slants of potato dextrose agar (PDA) at $25^{\circ} \mathrm{C}$ for 10 days. To prepare the seed culture, the agar plugs were added to three $250 \mathrm{~mL}$ flasks, each containing $50 \mathrm{~mL}$ sterile potato dextrose broth (PDB) media. Flask cultures were incubated at $25^{\circ} \mathrm{C}$ on a rotary shaker at $170 \mathrm{rpm}$ for 5 days. Large scale cultivation was carried out in twenty $500 \mathrm{~mL}$ Fernbach flasks each containing $60 \mathrm{~g}$ of rice and $90 \mathrm{~mL}$ of water. Each flask was inoculated with $5 \mathrm{~mL}$ of the spore inoculums and incubated at room temperature for 40 days.

2.3. Extraction and Isolation. The culture was extracted with EtOAc three times, and the organic solvent was evaporated 
under vacuum to yield the crude extract $(17.0 \mathrm{~g})$, which was subjected to silica gel column chromatography (CC) eluting with $\mathrm{CH}_{2} \mathrm{Cl}_{2}-\mathrm{CH}_{3} \mathrm{OH}(100: 0,100: 1,100: 2,100: 3$, and $100: 5)$ to afford five fractions (A-E). Fraction $\mathrm{C}(1.5 \mathrm{~g})$, eluting with $100: 2 \mathrm{CH}_{2} \mathrm{Cl}_{2}-\mathrm{CH}_{3} \mathrm{OH}$, was separated with Sephadex LH-20 column chromatography using $\mathrm{MeOH}$ as eluent to give two subfractions. Compound $\mathbf{8}(52.0 \mathrm{mg})$ was recrystallized from subfraction 1 with $\mathrm{MeOH}$, and subfraction 2 was subjected to semipreparative reversed phase HPLC $(35-100 \% \mathrm{MeOH}$ in $40 \mathrm{~min} ; 2 \mathrm{~mL} / \mathrm{min})$ to afford $10\left(2.5 \mathrm{mg} ; t_{\mathrm{R}} 20.4 \mathrm{~min}\right)$. Fraction $\mathrm{D}(56.0 \mathrm{mg})$ was further separated by Sephadex $\mathrm{LH}-20 \mathrm{CC}$ using $\mathrm{CH}_{3} \mathrm{OH}$ as eluent to afford two subfractions. Subfraction 1 was further purified by semipreparative reversed phase HPLC (28-50\% $\mathrm{MeCN}$ in $30 \mathrm{~min} ; 2 \mathrm{~mL} / \mathrm{min})$ to afford $4\left(2.0 \mathrm{mg} ; t_{\mathrm{R}} 17.7 \mathrm{~min}\right)$ and $2\left(3.0 \mathrm{mg} ; t_{\mathrm{R}} 19.3 \mathrm{~min}\right)$. Subfraction 2 was purified by semipreparative RP HPLC (47-75\% MeCN in $30 \mathrm{~min}$; $2 \mathrm{~mL} / \mathrm{min})$ to yield $7\left(5.0 \mathrm{mg} ; t_{\mathrm{R}} 15.7 \mathrm{~min}\right)$. The fraction $\mathrm{E}$ (200 mg) eluting with $100: 5 \mathrm{CH}_{2} \mathrm{Cl}_{2}-\mathrm{CH}_{3} \mathrm{OH}$ was separated by Sephadex $\mathrm{LH}-20 \mathrm{CC}$ eluted with $\mathrm{CH}_{3} \mathrm{OH}$ to afford two subfractions. One subfraction (110.3 mg) was purified by HPLC ( $35 \% \mathrm{MeOH}$ in $\mathrm{H}_{2} \mathrm{O}$ for $2 \mathrm{~min}$, followed by $35-100 \%$ $\mathrm{MeOH}$ for $42 \mathrm{~min} ; 2 \mathrm{~mL} / \mathrm{min}$ ) to afford $3\left(6.0 \mathrm{mg}, t_{\mathrm{R}} 17.5 \mathrm{~min}\right)$, $9\left(7.0 \mathrm{mg}, t_{\mathrm{R}} 13.0 \mathrm{~min}\right), \mathbf{1}\left(11.0 \mathrm{mg}, t_{\mathrm{R}} 14.2 \mathrm{~min}\right), 5(13.0 \mathrm{mg}$, $\left.t_{\mathrm{R}} 16.0 \mathrm{~min}\right)$, and $11\left(21.0 \mathrm{mg}, t_{\mathrm{R}} 21.6 \mathrm{~min}\right)$, and the other subfraction was subjected to reversed phase HPLC (28\% $\mathrm{MeOH}$ in $\mathrm{H}_{2} \mathrm{O}$ for $2 \mathrm{~min}$, followed by $28-50 \% \mathrm{MeOH}$ for $30 \mathrm{~min} ; 2 \mathrm{~mL} / \mathrm{min}$ ) to afford $6\left(12.0 \mathrm{mg} ; t_{\mathrm{R}} 24.5 \mathrm{~min}\right)$.

2.4. Absolute Configuration of the Secondary Alcohol in $\mathbf{1}$ and 5 [17, 18]. Compound 1 (2.0 mg) was treated with 2,2-dimethyoxypropane $(1.0 \mathrm{~mL})$ and pyridinium p-toluene sulfonate $(1.0 \mathrm{mg})$ and then stirred at $30^{\circ} \mathrm{C}$ for $5 \mathrm{~h}$ under $\mathrm{N}_{2}$ circumstance [19]. The reaction solution was evaporated in vacuum and purified by semipreparative reversed phase HPLC (50-100\% $\mathrm{CH}_{3} \mathrm{CN}$ in $\mathrm{H}_{2} \mathrm{O}$ for $30 \mathrm{~min} ; 2 \mathrm{~mL} / \mathrm{min}$ ) to yield the acetonide la $\left(1.0 \mathrm{mg}, t_{\mathrm{R}} 22.3 \mathrm{~min}\right)$; for ${ }^{1} \mathrm{H}$ NMR spectrum see Figure S32, in Supplementary Material available online at https://doi.org/10.1155/2017/6961928.

Compound $5(2.0 \mathrm{mg})$ was treated the same way as $\mathbf{1}$ to yield the acetonide $\mathbf{5 a}\left(0.5 \mathrm{mg}, t_{\mathrm{R}} 19.8 \mathrm{~min}\right)$ by semipreparative HPLC (50-100\% MeCN in $\mathrm{H}_{2} \mathrm{O}$ in $30 \mathrm{~min}, 2 \mathrm{~mL} / \mathrm{min}$ ); for ${ }^{1} \mathrm{H}$ NMR spectrum see Figure S33.

A sample of $1 \mathbf{a}(0.5 \mathrm{mg}$, or $5 \mathbf{a})$ was dissolved in a dry solution of the stock $\left[\mathrm{Rh}_{2}\left(\mathrm{OCOCF}_{3}\right)_{4}\right]$ complex $(1.5 \mathrm{mg})$ in $\mathrm{CH}_{2} \mathrm{Cl}_{2}(300 \mu \mathrm{L})$ and was subjected to $\mathrm{CD}$ measurements. The first $\mathrm{CD}$ spectrum was recorded immediately after mixing and its time evolution was monitored until being stationary (ca. $10 \mathrm{~min}$ after mixing). The inherent $\mathrm{CD}$ was subtracted. The observed sign of the $\mathrm{E}$ band at around $322 \mathrm{~nm}$ in the induced $\mathrm{CD}$ spectrum was correlated to the absolute configuration of the C-15 (or C-14) secondary alcohol moiety.

2.5. Cytotoxicity Bioassay. All the isolates were tested for their cytotoxicity against three human cancer cell lines A549, HepG 2, and Hela. The cancer cells were incubated in DMEM medium (HyClone, USA), added with $10 \%$ fetal bovine serum (HyClone, USA), and cultured in $5 \% \mathrm{CO}_{2}$ incubator at $37^{\circ} \mathrm{C}$. The cytotoxicity tests were performed according to the
MTT (3-(4,5-dimethylthiazol-2-yl)-2,5-diphenyl tetrazolium bromide) method [20], using etoposide as positive control.

2.6. Antibacterial Assay. A serial dilution method was employed for the determination of the antibacterial activities of the samples in triplicate, according to the National Center for Clinical Laboratory Standards (NCCLS) recommendations [21]. Three bacterial strains Staphylococcus aureus subsp. aureus (DSM 799), Escherichia coli (DSM 1116), and Bacillus subtilis (DSM 1088) were donated by Gang Li in School of Pharmacy, Qingdao University. Targeted microbes were prepared in MHB (Mueller-Hinton Broth) cultures, respectively, and the final spore suspensions of bacteria were $10^{6} \mathrm{CFU} / \mathrm{mL}$. Test compounds were transferred to 96-well clear plate, with DMSO solvent no more than $1 \%$ of the total volume. The suspensions of test organisms were added to each well, achieving a final volume of $100 \mu \mathrm{L}$ (streptomycin was used as positive control). After incubation $\left(37^{\circ} \mathrm{C}\right.$ for $24 \mathrm{~h}$ ), the absorbance at $595 \mathrm{~nm}$ was measured using a microtiter plate reader. The inhibition rate was measured and finally afforded the MIC values.

2.7. Antifungal Assay. Antifungal bioassays were also performed following the NCCLS recommendations, and six phytopathogenic fungi Botrytis cinerea (ACCC 37347), Verticillium dahliae (ACCC 36916), Fusarium oxysporum (ACCC 37438), Alternaria solani (ACCC 36023), Fusarium gramineum (ACCC 36249), and Rhizoctonia solani (ACCC 36124) were obtained from Agricultural Culture Collection of China (ACCC). Test microbes were cultured in Potato Dextrose Broth (PDB) and obtained the test concentrations of $10^{4}$ hyphae $/ \mathrm{mL}$. Test suspensions were added to each well achieving a final volume of $100 \mu \mathrm{L}$. Test compounds (dissolved in DMSO following serial dilutions) were transferred into each well (ketoconazole as positive control); after incubation $\left(28^{\circ} \mathrm{C}\right.$ for $\left.48 \mathrm{~h}\right)$, alamarBlue $(10 \mu \mathrm{L}$ of $10 \%$ solution) was added to each well as an indicator; then the fluorescence intensity was measured at $\mathrm{Ex} / \mathrm{Em}=544 / 590 \mathrm{~nm}$. The inhibition rate was calculated to afford MIC values. All the bioassays were performed in triplicate.

\section{Results and Discussion}

3.1. Structural Determinations of Isolated Compounds. Compound 1 was isolated as brown oil, $[\alpha]_{\mathrm{D}}{ }^{20}-43.1$ (c 0.12, methanol). Its molecular formula was determined to be $\mathrm{C}_{19} \mathrm{H}_{26} \mathrm{O}_{7}$ (seven degrees of unsaturation) on the basis of the pseudomolecular $[\mathrm{M}+\mathrm{Na}]^{+}$ion at $\mathrm{m} / z 389.1587$ (calcd 389.1576) together with consideration of NMR data. Its 1D NMR (Table 1, Figures S1 and S2) and HSQC data (Figure S5) showed resonances for two methyl groups, five methylenes (one oxygenated), three $O$-methines, six olefinic carbons (three of which were protonated), one oxygenated $s p^{3}$ quaternary carbon, one carboxylic carbon $\left(\delta_{\mathrm{C}} 171.2, \mathrm{C}-1\right)$, and one $\alpha, \beta$-unsaturated ketone carbon $\left(\delta_{\mathrm{C}} 196.0, \mathrm{C}\right.$-10). These data accounted for all the NMR resonances for 1 . The ${ }^{1} \mathrm{H}_{-}{ }^{1} \mathrm{H}$ COSY NMR data (Figure S3) of 1 showed the three isolated spin-systems of C-4-C-3-C-19 (allylic coupling between H3 and $\left.\mathrm{CH}_{3}-19\right)$, C-6-C-7, and C-11-C-17. HMBC correlations 
TABLE 1: ${ }^{1} \mathrm{H}$ and ${ }^{13} \mathrm{C}$ NMR spectroscopic data of compounds $\mathbf{1}-\mathbf{3}$ in $\mathrm{CD}_{3} \mathrm{OD}^{\mathrm{a}}$.

\begin{tabular}{|c|c|c|c|c|c|c|}
\hline \multirow{2}{*}{ Number } & \multicolumn{2}{|r|}{1} & \multicolumn{2}{|r|}{2} & \multicolumn{2}{|r|}{3} \\
\hline & $\delta_{\mathrm{C}}$ & $\delta_{\mathrm{H}}$ (mult., $J$ in $\mathrm{Hz}$ ) & $\delta_{\mathrm{C}}$ & $\delta_{\mathrm{H}}$ (mult., $J$ in $\mathrm{Hz}$ ) & $\delta_{\mathrm{C}}$ & $\delta_{\mathrm{H}}($ mult., $J$ in $\mathrm{Hz})$ \\
\hline (1) & 171.2 & & 172.8 & & 171.9 & \\
\hline (2) & 131.9 & & 133.3 & & 132.4 & \\
\hline (3) & 136.5 & $6.69, \mathrm{t}(7.8)$ & 134.3 & $6.61, \mathrm{t}(7.5)$ & 136.7 & $6.82, \mathrm{t}(7.5)$ \\
\hline \multirow{2}{*}{ (4) } & \multirow{2}{*}{28.8} & $2.78, \mathrm{dd}(15.9,7.6)$ & \multirow{2}{*}{28.6} & $2.75, \mathrm{dd}(15.9,8.0)$ & \multirow{2}{*}{31.8} & $2.61, \mathrm{dd}(16.0,8.0)$ \\
\hline & & 2.79, dd $(15.9,7.6)$ & & $2.80, \mathrm{dd}(15.9,8.0)$ & & 3.00 , dd $(16.0,8.0)$ \\
\hline (5) & 61.2 & & 61.5 & & 62.2 & \\
\hline (6) & 61.1 & $3.76, \mathrm{~d}(3.0)$ & 61.0 & $3.75, \mathrm{~d}(3.0)$ & 60.7 & 3.35 , br s \\
\hline (7) & 65.9 & 4.83 , br s & 65.8 & 4.72 , br s & 67.2 & 4.63 , br s \\
\hline (8) & 150.8 & & 145.5 & & 128.5 & \\
\hline (9) & 131.9 & & 134.9 & & 136.6 & \\
\hline (10) & 196.0 & & 195.8 & & 67.0 & $4.49, \mathrm{~s}$ \\
\hline (11) & 122.9 & $6.17, \mathrm{~d}(16.0)$ & 123.0 & $6.17 \mathrm{~d}(16.0)$ & 127.2 & $6.34, \mathrm{~d}(15.5)$ \\
\hline (12) & 139.9 & $5.88, \mathrm{dt}(16.0,8.4)$ & 140.5 & $5.83, \mathrm{dt}(16.0,7.0)$ & 135.5 & $6.01, \mathrm{dt}(15.0,8.0)$ \\
\hline (13) & 30.8 & $2.23, \mathrm{~m}$ & 30.8 & $2.17, \mathrm{~m}$ & 34.5 & $2.19, \mathrm{~m}$ \\
\hline (14) & 37.3 & $1.57, \mathrm{~m}$ & 37.3 & $1.56, \mathrm{~m}$ & 26.5 & $1.47, \mathrm{~m}$ \\
\hline (15) & 73.2 & $3.48, \mathrm{~m}$ & 73.2 & $3.46, \mathrm{~m}$ & 39.6 & $1.46, \mathrm{~m}$ \\
\hline (16) & 31.1 & $1.47, \mathrm{~m}$ & 31.1 & $1.47, \mathrm{~m}$ & 68.4 & $3.73, \mathrm{~m}$ \\
\hline (17) & 10.4 & $0.94, \mathrm{t}(8.4)$ & 10.4 & $0.94, \mathrm{t}(8.4)$ & 23.6 & $1.14, \mathrm{~d}(6.0)$ \\
\hline \multirow{2}{*}{ (18) } & \multirow{2}{*}{60.3} & $4.41, \mathrm{~d}(13.0)$ & \multirow{2}{*}{62.5} & $4.92, \mathrm{~d}(12.5)$ & \multirow{2}{*}{60.8} & \multirow{2}{*}{$4.86, \mathrm{~s}$} \\
\hline & & $4.52, \mathrm{~d}(13.0)$ & & $4.95, \mathrm{~d}(12.5)$ & & \\
\hline (19) & 12.8 & $1.86, \mathrm{~s}$ & 13.1 & $1.86, \mathrm{~s}$ & 13.0 & $1.86, \mathrm{~s}$ \\
\hline (20) & & & 172.4 & & 172.5 & \\
\hline (21) & & & 20.7 & $2.06, \mathrm{~s}$ & 20.9 & $2.02, \mathrm{~s}$ \\
\hline
\end{tabular}

${ }^{\mathrm{a}} \mathrm{H}-\mathrm{NMR}$ was recorded at $500 \mathrm{MHz} ;{ }^{13} \mathrm{C}-\mathrm{NMR}$ was recorded at $125 \mathrm{MHz}$.

(Figure S4) from H-4 to C-5, C-6, and C-10; from H-6 to C5, C-7, and C-8; from $\mathrm{H}-18$ to C-7, C-8, and C-9; from $\mathrm{H}-11$ to C-8, C-9, and C-10 established one cyclohex-2-en-one moiety with the C-4, C-18, and C-11 attached to C-5, C-8, and C-9, respectively. $\mathrm{HMBC}$ correlations from $\mathrm{H}-3$ to $\mathrm{C}-1$ and $\mathrm{C}-19$ and from $\mathrm{H}-19$ to $\mathrm{C}-1, \mathrm{C}-2$, and C-3 suggested a methyl and a carboxylic group located at C-2 (Figure 2). With comparison of NMR data of C-5 $\left(\delta_{\mathrm{C}} 61.2\right)$ and C-6 $\left(\delta_{\mathrm{C}} 61.1\right)$ with those of ambuic acid and its analogs, it demonstrated that these two carbons must form an epoxide ring. Molecular weight and the chemical shifts of $\mathrm{H}-15$ and $\mathrm{CH}_{2}-18$ implied that a hydroxyl group was attached at both carbons, respectively. On the basis of these data, the planar structure of $\mathbf{1}$ was proposed.

The relative configurations of 1 were deduced by the ${ }^{1} \mathrm{H}$ ${ }^{1} \mathrm{H}$ coupling constants and ROESY data (Figure S6). The C11/C-12, C-2/C-3 double bonds were assigned E-geometry on the basis of the large coupling constant $(J=16.0 \mathrm{~Hz})$ observed between $\mathrm{H}-11$ and $\mathrm{H}-12$ and ROESY correlation of $\mathrm{CH}_{2}-4$ with $\mathrm{CH}_{3}-19$. The small vicinal coupling constant $\left(J_{6,7}=3.0 \mathrm{~Hz}\right)$ suggested a cis orient between H-6 and H-7; the ROESY correlation of $\mathrm{H}-6$ with $\mathrm{CH}_{2}-4$ indicated these protons were on the same face of the cyclohex-2-en-one ring. The CD spectrum (Figure S7) of 1 showed positive (350 nm) and negative $(240 \mathrm{~nm})$ Cotton effects, which were similar to those of ambuic acid derivatives [11], macrophorin A [22], and (+)-epoxydon [23], suggesting the $5 R, 6 R$, and $7 R$ in structure 1 . The absolute configuration of the $\mathrm{C}-15$ secondary alcohol in 1 was deduced via the $\mathrm{CD}$ data of the in situ formed $\left[\mathrm{Rh}_{2}\left(\mathrm{OCOCF}_{3}\right)_{4}\right]$ complex with acetonide la (Figure 3$)$. The Rh-complex of la displayed a positive Cotton effects at near $323 \mathrm{~nm}$, suggesting the $15 S$ absolute configuration [17].

Compound 2 gave a molecular formula of $\mathrm{C}_{21} \mathrm{H}_{28} \mathrm{O}_{8}$ (eight degrees of unsaturation) by analysis of its HRESIMS $\left(m / z 431.1684[\mathrm{M}+\mathrm{Na}]^{+}\right)$. The extra 42 mass units compared to that of 1 suggested the presence of an acetyl group. Analysis of the 1D NMR spectroscopic data (Table 1) (Figures S8 and S9) and HSQC data (Figure S11) of 2 revealed structural similarity to those of $\mathbf{1}$, except that the oxygenated methylene protons $\left(\mathrm{CH}_{2}-18\right)$ were shifted downfield to $\delta_{\mathrm{H}}$ 4.90 and 4.96, respectively, in 2 . In addition, NMR resonances corresponding to an acetyl group $\left(\delta_{\mathrm{H}} 2.06 ; \delta_{\mathrm{C}} 20.7\right.$ and 172.4) were observed, indicating that the hydroxyl group attached at C-18 was acylated. This hypothesis was confirmed by an $\mathrm{HMBC}$ correlation (Figure S10) from $\mathrm{CH}_{2}-18$ to the carboxyl carbon at $\delta_{\mathrm{C}} 172.4$. Thus the gross structure of compound 2 was established as shown.

The relative configuration of $\mathbf{2}$ was the same as that of $\mathbf{1}$ by analysis of the ${ }^{1} \mathrm{H}-{ }^{1} \mathrm{H}$ coupling constants and ROESY data (Figure S12) of 2 . The absolute configuration of $\mathrm{C}$ $5, \mathrm{C}-6$, and C-7 in 2 was established on the basis of $\mathrm{CD}$ 


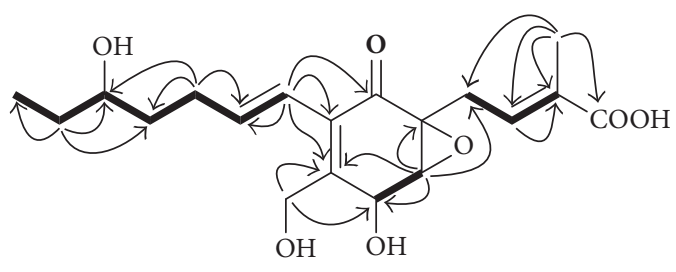

1

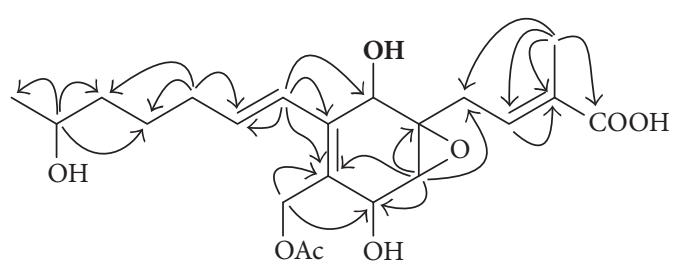

3

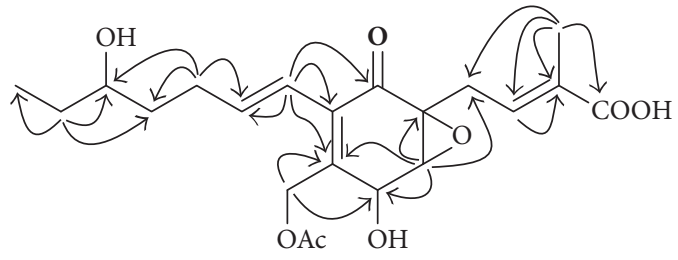

2

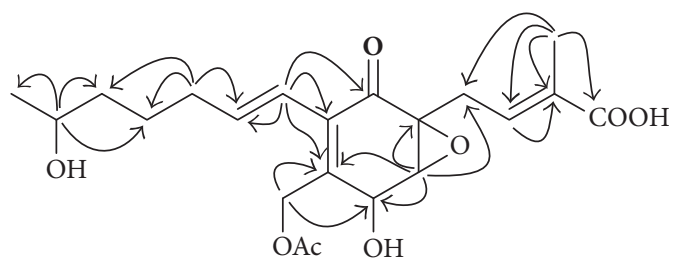

4

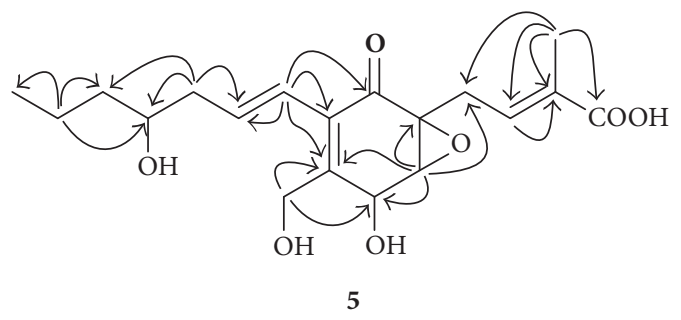

${ }^{1} \mathrm{H}-{ }^{1} \mathrm{H}$ COSY
$\longrightarrow \mathrm{HMBC}$

FIgURE $2:{ }^{1} \mathrm{H}-{ }^{1} \mathrm{H}$ COSY and key HMBC correlations of compounds 1-5.

data. The CD spectrum of 2 (Figure S13) showed positive (355 nm) and negative (243 nm) Cotton effects, indicating the $5 R, 6 R$, and $7 R$ configuration. From the view of biogenetic pathway together with considering the nearly same NMR data $(\mathrm{C} / \mathrm{H}-15)$ as that of the coisolated analog 1 , the absolute configuration of C-15 was postulated to be $S$.

The molecular formula of compound 3 was determined to be $\mathrm{C}_{21} \mathrm{H}_{30} \mathrm{O}_{8}$ (seven degrees of unsaturation) on the basis of HRESIMS analysis $\left(m / z 433.1848[\mathrm{M}+\mathrm{Na}]^{+}\right)$. Analysis of the ${ }^{1} \mathrm{H}$ and ${ }^{13} \mathrm{C}$ NMR (Table 1) (Figures S14 and S15) together with HSQC data (Figure S17) indicated that 3 possess similar structure to that of the known compound (number 4 in the paper) reported by Qi and coworkers except that an additional hydroxyl group as a multiplet was found in 3 [12]. The HMBC correlations (Figure S16) confirmed that the hydroxy moiety was anchored at C-16. Thus the planar configuration of $\mathbf{3}$ was determined.

The relative configurations for C-5, C-6, and C-7 in 3 were deduced to be the same as those in $\mathbf{1}$ by comparison of the coupling constants and ROESY data (Figure S18). In ROESY experiment of 3, the cross-peaks from $\mathrm{H}-10$ to $\mathrm{H}-4, \mathrm{H}-6$, and $\mathrm{H}-7$ suggested that $\mathrm{H}-10, \mathrm{H}_{2}-4, \mathrm{H}-6$, and $\mathrm{H}-7$ were on the same face of the cyclohex-2-en-one ring. The CD spectrum of 3 (Figure S19) showed negative Cotton effects in the regions of $238 \mathrm{~nm}$ the same as that of known analog [12]. Therefore, compound 3 was deduced to have the $5 S, 6 R, 7 R$, and $10 S$ except the C-16.

The molecular formula of compound 4 was determined to be $\mathrm{C}_{21} \mathrm{H}_{28} \mathrm{O}_{8}$ (eight degrees of unsaturation) on the basis of HRESIMS analysis $\left(\mathrm{m} / z 431.1692[\mathrm{M}+\mathrm{Na}]^{+}\right)$with less 2 mass units compared to that of 3 , suggesting the presence of an additional unsaturation degree. Detailed analysis of the NMR spectra (Table 2) (Figures S20 and S21) together with HSQC data (Figure S23) especially the ${ }^{13} \mathrm{C}$ NMR (C-8 and C-9) confirmed that the oxymethine (C-10) in 3 must be oxidized to be the corresponding ketogroup in 4 , which shaped $\alpha, \beta$-unsaturated double bond leading to the chemical shift value of $\mathrm{C}-8$ to be downfielded. This conclusion was further confirmed by HMBC correlations (Figure S22) from $\mathrm{CH}_{2}-4, \mathrm{H}-6$, and $\mathrm{H}-11$ to the ketogroup $\left(\delta_{\mathrm{C}} 195.4, \mathrm{C}-10\right)$.

The relative configurations of 4 for C-5, C-6, and C-7 were determined in the same way with 3 on the basis of the coupling constants and ROESY data (Figure S24). The CD data (S25) displayed the same Cotton curves as those $\mathbf{1}$ and $\mathbf{2}$, 
<smiles>CC[C@H](O)CC/C=C/C1=C2COC(C)(C)O[C@H]2[C@H]2C[C@]1(C/C=C(\C)C(=O)O)C2=O</smiles>

1a

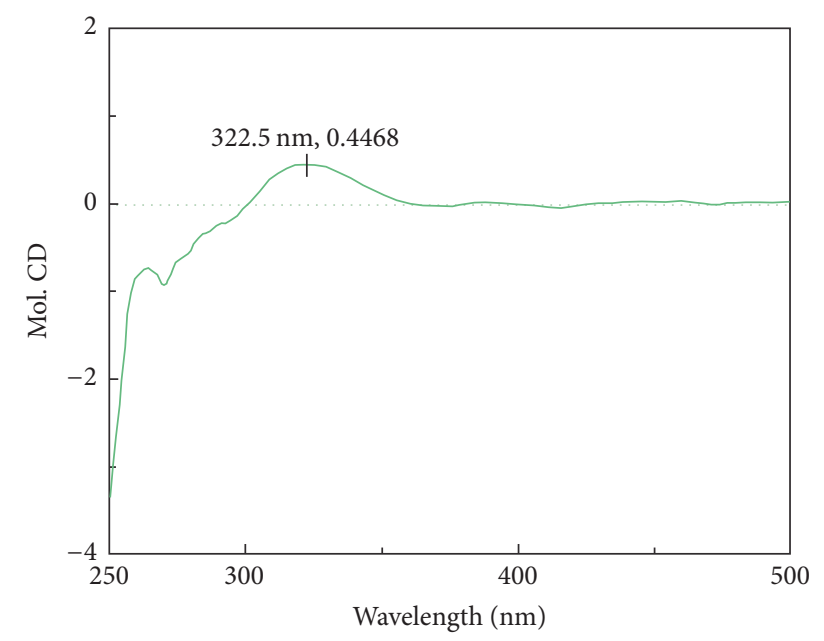

FIGURE 3: CD spectrum of Rh-complex of 1a with the inherent contributions subtracted.
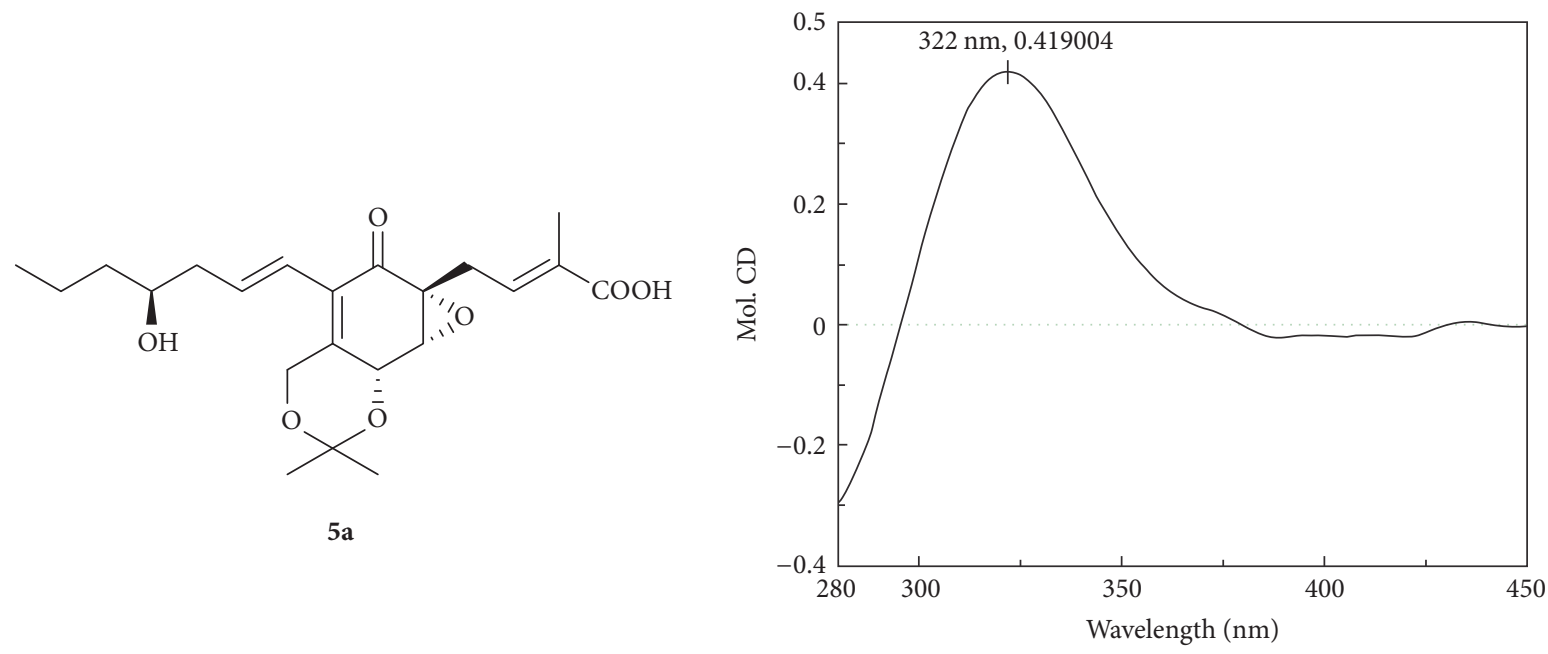

FIGURE 4: CD spectrum of Rh-complex of 5a with the inherent contributions subtracted.

which established the absolute configuration of 4 as $5 R, 6 R$, and $7 R$. Modified Mosher's reaction was tried to determine the absolute configuration of C-16 in $\mathbf{3}$ and $\mathbf{4}$, but it was not successful. Thus consideration of biosynthetic pathway and nearly the same NMR data as those $\mathbf{9}$ and $\mathbf{1 0}$ at C-16 implied their same stereochemistry.

Compound 5 was assigned the molecular formula $\mathrm{C}_{19} \mathrm{H}_{26} \mathrm{O}_{7}$ (seven degrees of unsaturation) by HRESIMS $\left(m / z=389.1584[\mathrm{M}+\mathrm{Na}]^{+}\right)$. Comparison of the 1D NMR spectroscopic data (Figures S26 and S27) of 5 with those of 1 revealed that chemical shift values of $\mathrm{H} / \mathrm{C}-15\left(\delta_{\mathrm{H}} 3.64 ; \delta_{\mathrm{C}}\right.$ $71.9)$ in 1 were transferred to $\delta_{\mathrm{H}} 3.48$ and $\delta_{\mathrm{C}} 73.2$, respectively, in 5, together with HSQC data (Figure S29), suggesting that the position of hydroxyl on aliphatic chain was changed in those two compounds. HMBC correlations (Figure S28) confirmed that $\mathrm{C}-14$ possessed a free hydroxyl group. The relative configurations for $\mathrm{C}-5, \mathrm{C}-6$, and $\mathrm{C}-7$ in 5 were deduced to be the same as those in $\mathbf{1}$ by comparison of the ${ }^{1} \mathrm{H}-{ }^{1} \mathrm{H}$ coupling constants and ROESY data (Figure S30). The CD spectrum of 5 (Figure S31) was identical to that of 1 , showing the $5 R, 6 R$, and $7 R$ absolute configuration. The stereochemistry of the C-14 secondary alcohol was deduced via the $\mathrm{CD}$ data of the in situ formed $\left[\mathrm{Rh}_{2}\left(\mathrm{OCOCF}_{3}\right)_{4}\right]$ complex with acetonide $\mathbf{5 a}$ (Figure 4 ). The Rh-complex of $\mathbf{5 a}$ displayed positive Cotton effects at near $322 \mathrm{~nm}$, suggesting the $14 S$ absolute configuration [17].

The structures of known compounds (6-11) were determined by NMR data analyses and comparison with the literature data [10-12].

Compound 1. Brown oil (MeOH); $[\alpha]_{\mathrm{D}}^{25}-43.1$ (c 0.12, methanol); UV (methanol) $\lambda_{\max }(\log \varepsilon): 210$ (3.83), 270 (3.20), 303 (3.02) nm; CD $\left(c 5.5 \times 10^{-3} \mathrm{M}\right.$, methanol): $\lambda(\Delta \varepsilon)$ 220 (2.22), 240 (-0.44), 277 (0.78), 352 (0.22); IR (neat) 


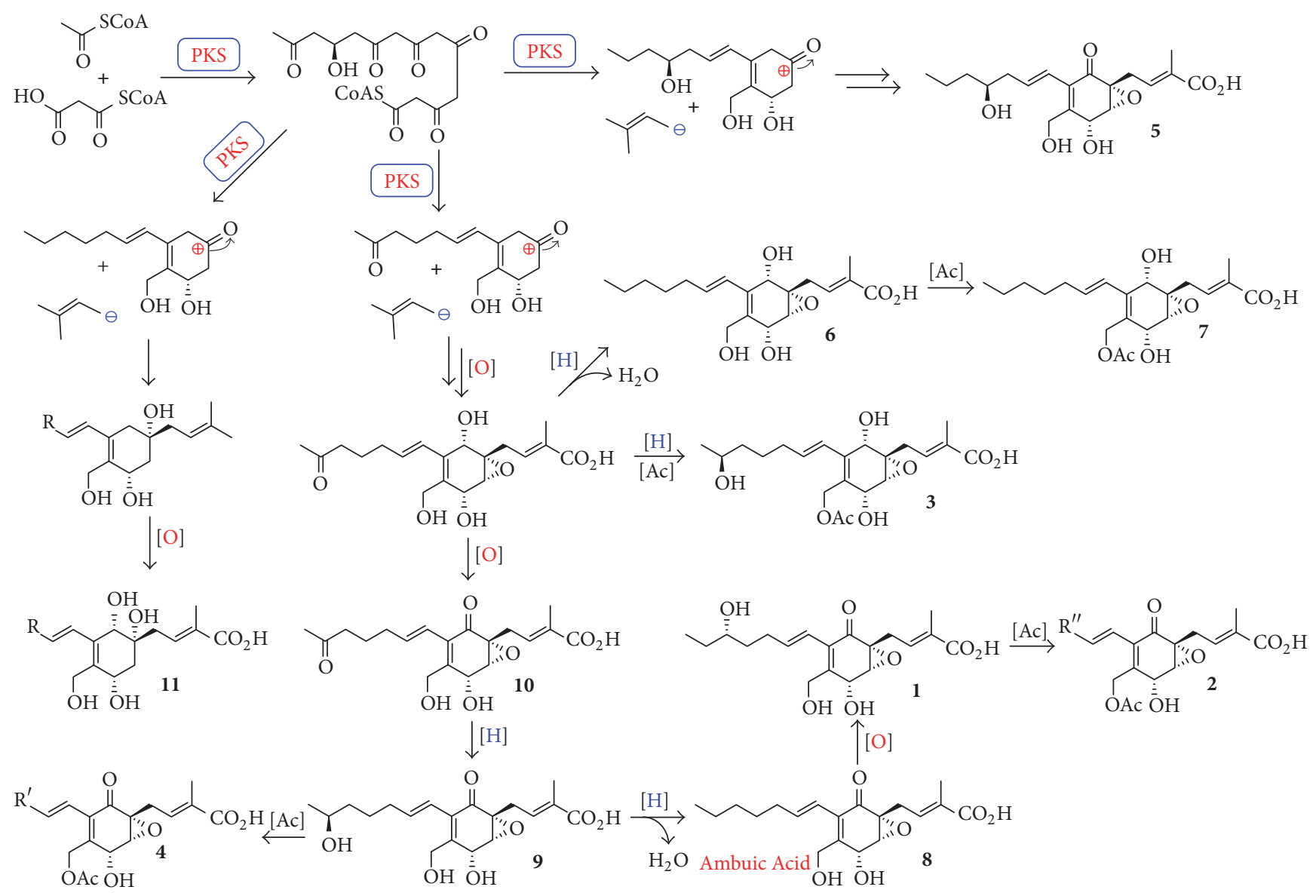

FIGURE 5: The possible biosynthetic pathway of ambuic acid and its analogs.

$v_{\max }: 3384$ (br), 2937, 2878, 1680, 1447, 1382, 1263, $1022 \mathrm{~cm}^{-1}$; for ${ }^{1} \mathrm{H}$ NMR and ${ }^{13} \mathrm{C}$ NMR data see Table 1; Positive HRESI-MS: $m / z 389.1587[\mathrm{M}+\mathrm{Na}]^{+}$(calcd. for $\mathrm{C}_{19} \mathrm{H}_{26} \mathrm{O}_{7} \mathrm{Na}$, 389.1576).

Compound 2. Brown oil (MeOH); $[\alpha]_{\mathrm{D}}^{25} 5.0$ (c 0.025 , methanol); UV (methanol) $\lambda_{\max }(\log \varepsilon): 211$ (3.03); CD (c 4.6× $10^{-3} \mathrm{M}$, methanol): $\lambda(\Delta \varepsilon) 216(0.20), 267$ (6.85), $356(0.21)$; IR (neat) $v_{\max }: 3380$ (br), 2963, 2933, 2878, 1689, 1436, 1381, 1253, 1081, $1026 \mathrm{~cm}^{-1}$; for ${ }^{1} \mathrm{H}$ NMR and ${ }^{13} \mathrm{C}$ NMR data see Table 1; Positive HR-ESI-MS: $m / z$ 431.1684 [M + Na ${ }^{+}$(calcd. for $\mathrm{C}_{21} \mathrm{H}_{28} \mathrm{O}_{8} \mathrm{Na}, 431.1682$ ).

Compound 3. Brown oil (MeOH); $[\alpha]_{\mathrm{D}}^{25}-140.0$ (c 0.1 , methanol); UV (methanol) $\lambda_{\text {max }}(\log \varepsilon): 211$ (4.80) nm; CD $(c$ $2.3 \times 10^{-3} \mathrm{M}$, methanol): $\lambda(\Delta \varepsilon) 207$ (3.43), 239 (-13.99); IR (neat) $v_{\max }: 3383$ (br), 2965, 2933, 2660, 1694, 1652, 1557, 1377, 1252, $1130,1025 \mathrm{~cm}^{-1}$; for ${ }^{1} \mathrm{H}$ NMR and ${ }^{13} \mathrm{C}$ NMR data see Table 1; Positive HR-ESI-MS: $m / z 433.1848[\mathrm{M}+\mathrm{Na}]^{+}$(calcd. for $\mathrm{C}_{21} \mathrm{H}_{30} \mathrm{O}_{8} \mathrm{Na}, 433.1838$ ).

Compound 4. Brown oil (MeOH); $[\alpha]_{\mathrm{D}}^{25} 250.0$ (c 0.1 , methanol); UV (methanol) $\lambda_{\text {max }}(\log \varepsilon): 211$ (4.54) nm; CD $(c$ $2.3 \times 10^{-3} \mathrm{M}$, methanol): $\lambda(\Delta \varepsilon) 223$ (2.50), 268 (8.45), 354 (1.15); IR (neat) $v_{\max }: 3353$ (br), 2965, 2934, 1684, 1646, 1447,
1374, 1256, 1130, 1079, $1026 \mathrm{~cm}^{-1}$; for ${ }^{1} \mathrm{H}$ NMR and ${ }^{13} \mathrm{C}$ NMR data see Table 2; Positive HR-ESI-MS: $m / z$ 431.1692 [M + $\mathrm{Na}]^{+}$(calcd. for $\mathrm{C}_{21} \mathrm{H}_{28} \mathrm{O}_{8} \mathrm{Na}, 431.1682$ ).

Compound 5. Brown oil (MeOH); $[\alpha]_{\mathrm{D}}^{25}-80.0$ (c 0.1 , methanol); UV (methanol) $\lambda_{\max }$ (log $\varepsilon$ ): 213 (4.22), 299 (3.56) $\mathrm{nm}$; CD $\left(\right.$ c $5.1 \times 10^{-3} \mathrm{M}$, methanol): $\lambda(\Delta \varepsilon) 223$ (1.33), 273 (1.23); IR (neat) $v_{\text {max }}: 3393$ (br), 2959, 2933, 2873, 1680, 1647, 1437, 1380, 1260, $1022 \mathrm{~cm}^{-1}$; for ${ }^{1} \mathrm{H}$ NMR and ${ }^{13} \mathrm{C}$ NMR data see Table 2; Positive HR-ESI-MS: $m / z 389.1584[\mathrm{M}+\mathrm{Na}]^{+}$ (calcd. for $\mathrm{C}_{19} \mathrm{H}_{26} \mathrm{O}_{7} \mathrm{Na}, 389.1576$ ).

3.2. Proposed Biosynthetic Pathway of 1-11. Analysis of the structural features of ambuic acid and its analogs implied their biosynthesis originated from polyketide-terpene hybrid, and the biogenetic pathway was first suggested as shown in Figure 5. Ambuic acid and its analogs possess a highly functionalized cyclohexenone ring, and, considering their biosynthesis, their biosynthesis demonstrated that the postmodification enzymes especially oxidase play a vital role in the formation of chemical diversity.

3.3. Biological Activities. Compounds 1-11 were evaluated against several tumor cells including A549, HepG 2, and Hela 
TABLE 2: ${ }^{1} \mathrm{H}$ and ${ }^{13} \mathrm{C}$ NMR spectroscopic data of compounds 4 and 5 in $\mathrm{CD}_{3} \mathrm{OD}^{\mathrm{a}}$.

\begin{tabular}{|c|c|c|c|c|}
\hline \multirow{2}{*}{ Number } & \multicolumn{2}{|c|}{4} & \multicolumn{2}{|c|}{5} \\
\hline & $\delta_{\mathrm{C}}$ & $\delta_{\mathrm{H}}$ (mult., $J$ in $\mathrm{Hz}$ ) & $\delta_{\mathrm{C}}$ & $\delta_{\mathrm{H}}$ (mult., $J$ in $\mathrm{Hz}$ ) \\
\hline (1) & 171.6 & & 171.6 & \\
\hline (2) & 132.4 & & 132.2 & \\
\hline (3) & 136.0 & $6.66, \mathrm{t}(7.0)$ & 136.2 & $6.67, \mathrm{t}(7.0)$ \\
\hline \multirow{2}{*}{ (4) } & \multirow{2}{*}{28.6} & 2.77, dd $(15.5,7.0)$ & \multirow{2}{*}{28.8} & 2.75 , dd $(15.5,7.5)$ \\
\hline & & $2.80, \mathrm{dd}(15.5,7.0)$ & & $2.82, \mathrm{dd}(15.5,7.5)$ \\
\hline (5) & 61.4 & & 61.3 & \\
\hline (6) & 61.0 & $3.75, \mathrm{~d}(3.0)$ & 61.1 & $3.76, \mathrm{~d},(3.0)$ \\
\hline (7) & 65.8 & 4.72 , br s & 65.9 & 4.83 , br s \\
\hline (8) & 145.5 & & 151.1 & \\
\hline (9) & 134.3 & & 131.8 & \\
\hline (10) & 195.4 & & 196.1 & \\
\hline (11) & 123.0 & $6.32, \mathrm{~d}(16.5)$ & 124.9 & $6.19, \mathrm{~d}(16.0)$ \\
\hline (12) & 140.6 & $5.86, \mathrm{dt}(16.0,7.0)$ & 136.5 & $5.91, \mathrm{dt}(16.0,7.5)$ \\
\hline (13) & 34.5 & $2.18, \mathrm{~m}$ & 42.6 & $2.30, \mathrm{~m}$ \\
\hline (14) & 26.4 & $1.47, \mathrm{~m}$ & 71.9 & $3.64, \mathrm{~m}$ \\
\hline (15) & 39.6 & $1.45, \mathrm{~m}$ & 40.2 & $1.44, \mathrm{~m}$ \\
\hline (16) & 68.4 & $3.74, \mathrm{~m}$ & 19.9 & $1.48, \mathrm{~m}$ \\
\hline (17) & 23.6 & $1.14, \mathrm{t}(6.5)$ & 14.4 & $0.93, \mathrm{t}(7.0)$ \\
\hline \multirow{2}{*}{ (18) } & \multirow{2}{*}{62.5} & $4.91, \mathrm{~d}(12.5)$ & \multirow{2}{*}{60.3} & 4.41, d (12.5) \\
\hline & & $4.96, \mathrm{~d}(12.5)$ & & $4.53, \mathrm{~d}(12.5)$ \\
\hline (19) & 12.9 & $1.86, \mathrm{~s}$ & 12.8 & $1.86, \mathrm{~s}$ \\
\hline$(20)$ & 172.4 & & & \\
\hline (21) & 20.7 & $2.05, \mathrm{~s}$ & & \\
\hline
\end{tabular}

${ }^{\mathrm{a} 1} \mathrm{H}-\mathrm{NMR}$ was recorded at $500 \mathrm{MHz} ;{ }^{13} \mathrm{C}-\mathrm{NMR}$ was recorded at $125 \mathrm{MHz}$.

TABle 3: Minimum Inhibitory Concentrations (MIC) of compounds 1-11 against six plant pathogenic fungi ${ }^{\mathrm{a}}$.

\begin{tabular}{|c|c|c|c|c|c|c|}
\hline Compounds & Botrytis cinerea & Verticillium dahlia & Fusarium oxysporum & Alternaria solani & Fusarium gramineum & Rhizoctonia solani \\
\hline 1 & $>64$ & 64 & 8 & $>64$ & $>64$ & $>64$ \\
\hline 2 & $>64$ & 64 & 32 & $>64$ & $>64$ & $>64$ \\
\hline 3 & $>64$ & 64 & 64 & $>64$ & $>64$ & 64 \\
\hline 4 & $>64$ & 32 & 64 & $>64$ & $>64$ & $>64$ \\
\hline 5 & $>64$ & 16 & 8 & $>64$ & 8 & 64 \\
\hline 6 & $>64$ & 64 & 64 & $>64$ & 8 & 64 \\
\hline 7 & $>64$ & $>64$ & $>64$ & $>64$ & 64 & 32 \\
\hline 8 & $>64$ & $>64$ & 64 & $>64$ & 64 & 32 \\
\hline 9 & $>64$ & 64 & 16 & $>64$ & 32 & $>64$ \\
\hline 10 & $>64$ & 64 & $>64$ & $>64$ & 64 & $>64$ \\
\hline 11 & $>64$ & 64 & $>64$ & $>64$ & 32 & 64 \\
\hline Ketoconazole & 16 & 1 & 8 & 16 & 8 & 8 \\
\hline
\end{tabular}

${ }^{\mathrm{a}}$ All values are in $\mu \mathrm{g} / \mathrm{mL}$.

cell lines by MTT colorimetric method [20] using etoposide as positive control $\left(\mathrm{IC}_{50}\right.$ values $16.46 \pm 1.22,16.11 \pm 0.10$, and $15.00 \pm 0.23 \mu \mathrm{M}$, respectively). Unfortunately, none of these ambuic acid analogs showed significant cytotoxicity $\left(\mathrm{IC}_{50}>\right.$ $40 \mu \mathrm{M})$ against the tested cancer cell lines. Compounds 1-11 were also evaluated against Staphylococcus aureus (DSM 799), Escherichia coli (DSM 1116), and Bacillus subtilis (DSM 1088 ) without any bioactivities (MIC $>64 \mu \mathrm{g} / \mathrm{mL}$, positive control as streptomycin, MIC values 5,1 , and $5 \mu \mathrm{g} / \mathrm{mL}$, resp.). In addition, the antifungal activities against six plant pathogens Botrytis cinerea, Verticillium dahlia, Fusarium oxysporum, Alternaria solani, Fusarium gramineum, and Rhizoctonia solani displayed that $\mathbf{1}$ and $\mathbf{5}$ exhibited pronounced biological effects against $F$. oxysporum with MIC value of $8 \mu \mathrm{g} / \mathrm{mL}$, whereas 5 and $\mathbf{6}$ can potently inhibit F. gramineum at concentration of $8 \mu \mathrm{g} / \mathrm{mL}$, compared with the positive control ketoconazole (MIC value of $8 \mu \mathrm{g} / \mathrm{mL}$ ) (Table 3). Our biological evaluation results further supported that ambuic 
acid analogs might possess potential bioactivities against pathogens, without biological effects against bacteria.

\section{Conclusion}

In summary, five new metabolites (1-5) with highly functionalized groups, together with six known derivatives (6-11), were isolated from the endolichenic fungus Pestalotiopsis sp. Cytotoxicity and antimicrobial bioassays were performed and the results revealed that compound $\mathbf{1}$ and $\mathbf{5}$ can significantly inhibit the growth of plant pathogenic fungus F. oxysporum, and compounds 5 and $\mathbf{6}$ potently inhibited F. gramineum, with MIC value of $8 \mu \mathrm{g} / \mathrm{mL}$, and these results might reveal the possible ecological role of endolichenic fungus for providing chemical protection for its host plants in the fungus-plant relationship. Our results also implied the potentiality of compound 1, 5, and $\mathbf{6}$ as suitable fungicides in application of agricultural crop protection. Analysis of the structural features of ambuic acid and its analogs implied their biosynthesis originated from polyketide-terpene hybrid, and the biogenetic pathway was suggested for the first time, which is helpful in its further biosynthesis research, because ambuic acid derivatives were unique to the genus Pestalotiopsis, which suggest their contributions as diagnostic metabolites in the chemical taxonomy of Pestalotiopsis sp.

\section{Conflicts of Interest}

The authors have declared that there are no conflicts of interest.

\section{Authors' Contributions}

Chao Yuan and Gang Ding contributed equally to this work.

\section{Acknowledgments}

The authors gratefully acknowledge financial support from the National Natural Science Foundation of China (no. 31400110), PUMC Youth Fund and the Fundamental Research Funds for the Central Universities (no. 3332015146), Program for Innovative Research Team in IMPLAD (IT1305), and Special Fund for Basic Scientific Research from Yunnan Branch of IMPLAD at CAMS \& PUMC (YZYN-15-03).

\section{References}

[1] Y.-B. Zheng, D.-X. Chen, J.-J. Li, and J.-Z. Huang, "New sesquiterpenoid from Pestalotiopsis sp.", Chinese Journal of Natural Medicines, vol. 9, no. 6, pp. 421-424, 2011.

[2] J. Xu, A. H. Aly, V. Wray, and P. Proksch, "Polyketide derivatives of endophytic fungus Pestalotiopsis sp. isolated from the Chinese mangrove plant Rhizophora mucronata," Tetrahedron Letters, vol. 52, no. 1, pp. 21-25, 2011.

[3] G. A. Strobel, W. M. Hess, E. Ford, R. S. Sidhu, and X. J. Yang, "Taxol from fungal endophytes and the issue of biodiversity," Journal of Industrial Microbiology \& Biotechnology, vol. 17, no. 5, pp. 417-423, 1996.
[4] J.-Y. Li, G. Strobel, R. Sidhu, W. M. Hess, and E. J. Ford, "Endophytic taxol-producing fungi from bald cypress, Taxodium distichum," Microbiology, vol. 142, no. 8, pp. 2223-2226, 1996.

[5] A. E. Arnold, "Understanding the diversity of foliar endophytic fungi: progress, challenges, and frontiers," Fungal Biology Reviews, vol. 21, no. 2-3, pp. 51-66, 2007.

[6] K.-H. Nguyen, M. Chollet-Krugler, N. Gouault, and S. Tomasi, "UV-protectant metabolites from lichens and their symbiotic partners," Natural Product Reports, vol. 30, no. 12, pp. 1490-1508, 2013.

[7] Y. L. Dou, X. L. Wang, D. F. Jiang et al., "Metabolites from Aspergillus versicolor, an endolichenic fungus from the lichen Lobaria retigera," Drug Discoveries and Therapeutics, vol. 8, no. 2, pp. 8488, 2014.

[8] J.-W. He, G.-D. Chen, H. Gao et al., "Heptaketides with antiviral activity from three endolichenic fungal strains Nigrospora sp., Alternaria sp. and Phialophora sp.", Fitoterapia, vol. 83, no. 6, pp. 1087-1091, 2012.

[9] X. B. Li, Y. H. Zhou, R. X. Zhu et al., "Identification and biological evaluation of secondary metabolites from the endolichenic fungus Aspergillus versicolor," Chemistry and Biodiversity, vol. 12, pp. 575-592, 2015.

[10] J. Y. Li, J. K. Harper, D. M. Grant et al., "Ambuic acid, a highly functionalized cyclohexenone with antifungal activity from Pestalotiopsis spp. and Monochaetia sp.", Phytochemistry, vol. 56, no. 5, pp. 463-468, 2001.

[11] G. Ding, Y. Li, S. Fu, S. Liu, J. Wei, and Y. Che, "Ambuic acid and torreyanic acid derivatives from the endolichenic fungus Pestalotiopsis sp," Journal of Natural Products, vol. 72, no. 1, pp. 182-186, 2009.

[12] Q.-Y. Qi, E.-W. Li, J.-J. Han et al., "New ambuic acid derivatives from the solid culture of Pestalotiopsis neglecta and their nitric oxide inhibitory activity," Scientific Reports, vol. 5, article 9958, 2015.

[13] G. Ding, H. Wang, L. Li et al., "Trichodermone, a spiro-cytochalasan with a tetracyclic nucleus $(7 / 5 / 6 / 5)$ skeleton from the plant endophytic fungus Trichoderma gamsii," Journal of Natural Products, vol. 77, no. 1, pp. 164-167, 2014.

[14] Y. Wang, S. Niu, S. Liu, L. Guo, and Y. Che, "The first naturally occurring thiepinols and thienol from an endolichenic fungus Coniochaeta sp.", Organic Letters, vol. 12, no. 21, pp. 5081-5083, 2010.

[15] G. Ding, F. Zhang, H. Chen, L. Guo, Z. Zou, and Y. Che, "Pestaloquinols $\mathrm{A}$ and $\mathrm{B}$, isoprenylated epoxyquinols from Pestalotiopsis sp." Journal of Natural Products, vol. 74, no. 2, pp. 286291, 2011.

[16] G. Li, H. Wang, R. Zhu et al., "Phaeosphaerins A-F, cytotoxic perylenequinones from an endolichenic fungus, Phaeosphaeria sp.," Journal of Natural Products, vol. 75, no. 2, pp. 142-147, 2012.

[17] J. Frelek and W. J. Szczepek, " $\left[\mathrm{Rh}_{2}(\mathrm{OCOCF} 3)_{4}\right]$ as an auxiliary chromophore in chiroptical studies on steroidal alcohols," Tetrahedron Asymmetry, vol. 10, no. 8, pp. 1507-1520, 1999.

[18] M. Gerards and G. Snatzke, "Circular dichroism, XCIII determination of the absolute configuration of alcohols, olefins, epoxides, and ethers from the $\mathrm{CD}$ of their 'in situ' complexes with $\left[\mathrm{Rh}_{2}\left(\mathrm{O}_{2} \mathrm{CCF}_{3}\right)_{4}\right]$," Tetrahedron: Asymmetry, vol. 1, no. 4, pp. 221-236, 1990.

[19] J. Liu, Y. Liu, Y. Si et al., "New vernocuminosides from the stem barks of Vernonia cumingiana Benth," Steroids, vol. 74, no. 1, pp. 51-61, 2009. 
[20] T. Mosmann, "Rapid colorimetric assay for cellular growth and survival: application to proliferation and cytotoxicity assays," Journal of Immunological Methods, vol. 65, no. 1-2, pp. 55-63, 1983.

[21] NCCLS, NCCLS document M38-A, NCCLS, Wayne, Pa, USA, 2002.

[22] T. Sassa and H. Yoshikoshi, "New terpene-linked cyclohexenone epoxides, macrophorin $\mathrm{A}, \mathrm{B}$ and $\mathrm{C}$, produced by the fungus caused macrophoma fruit rot of apple," Agricultural and Biological Chemistry, vol. 47, no. 1, pp. 187-189, 1983.

[23] J. Sekiguchi and G. M. Gaucher, "Isoepoxydon, a new metabolite of the patulin pathway in Penicillium urticae," Biochemical Journal, vol. 182, no. 2, pp. 445-453, 1979. 

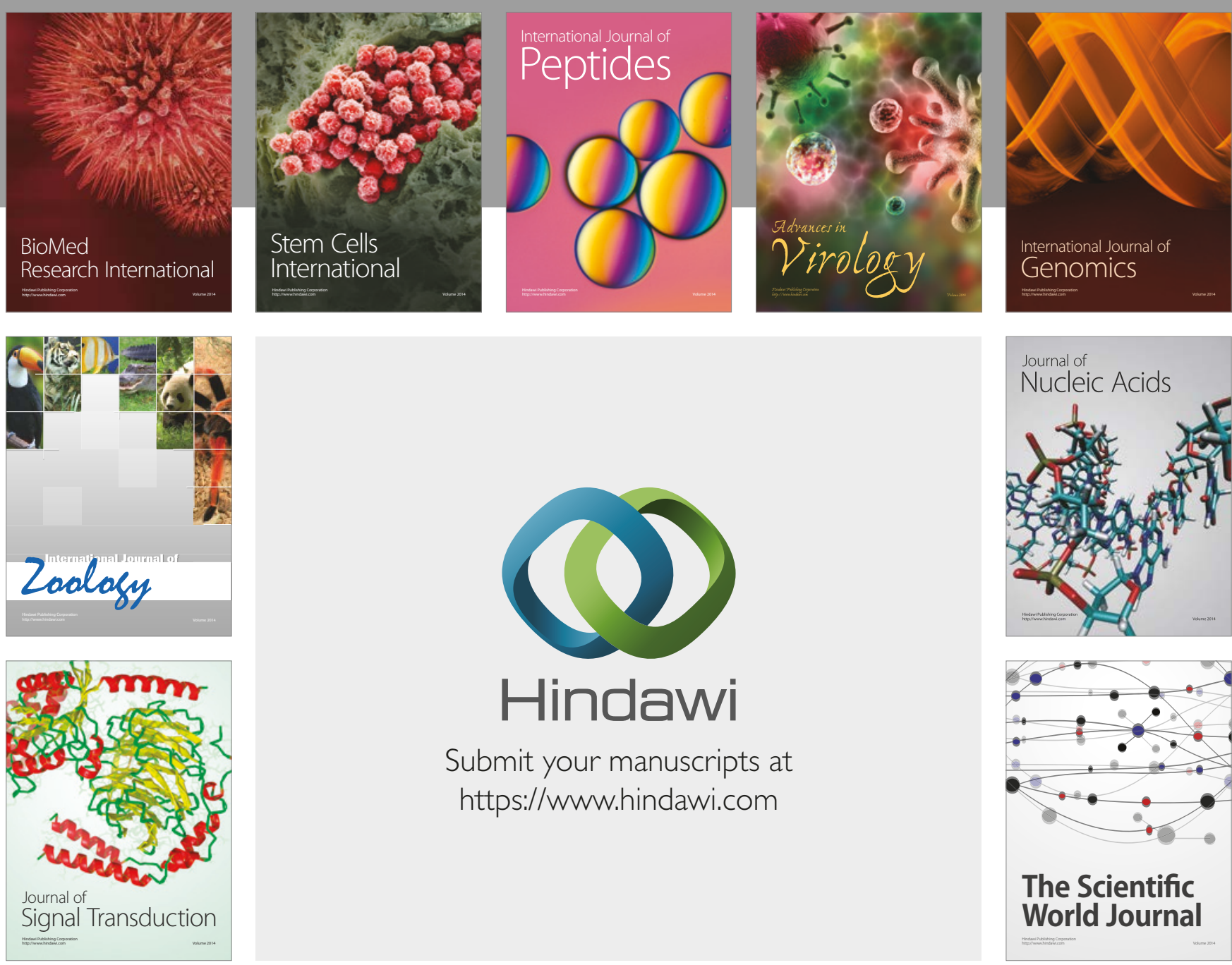

Submit your manuscripts at

https://www.hindawi.com
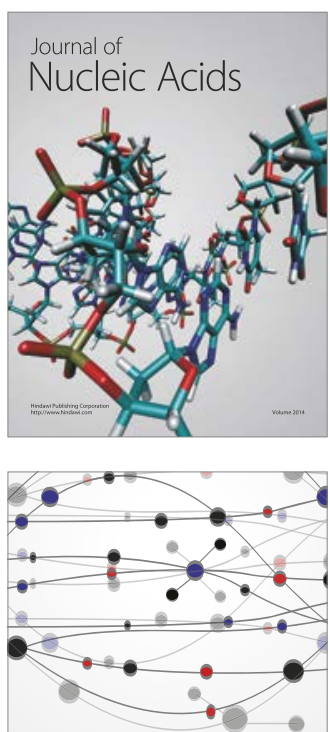

The Scientific World Journal

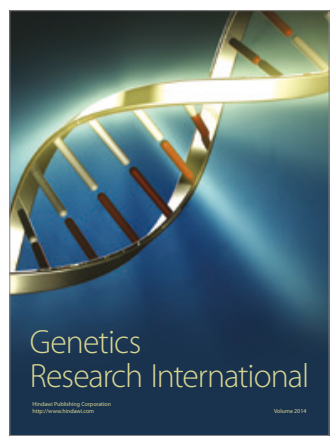

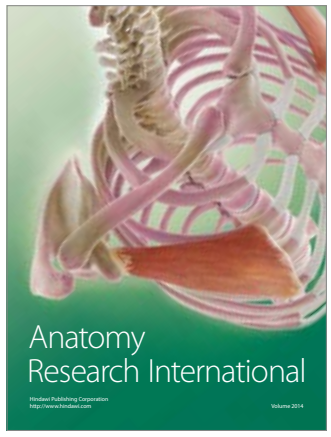

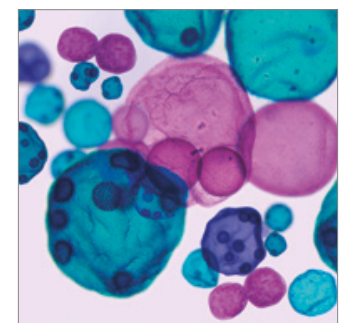

International Journal of Microbiology
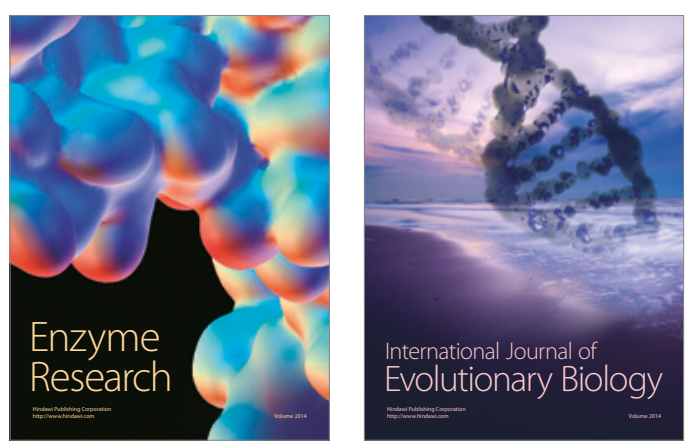
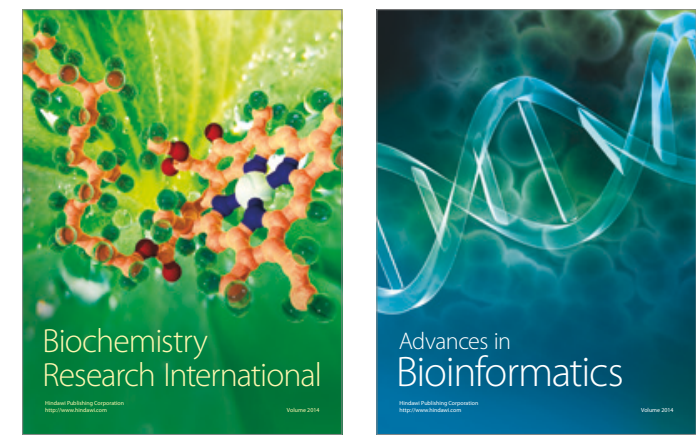

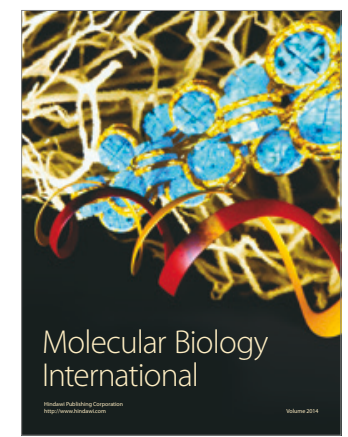

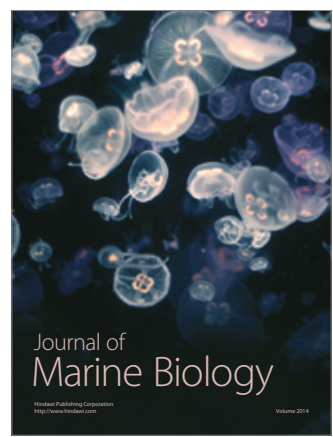

